\title{
GEORGE NIDEVER: 1878
}

7 HE SUBJECr of this sketch, although already over 76 yrs. 1 of age, ${ }^{*}$ is still strong and active. He is about the medium height and inclined to be stout. He stoops the least bit but it may be from habit rather than old age. His sight and hearing are still keen and his nerves remarkably steady for one so old. He lives with his youngest daughter and wife, about a mile from town, on a piece of land containing several acres. It is under cultivation and he keeps it free from squirrels by shooting them with a Colt's revolver. If a chicken is wanted for dinner he prefers shooting its head off with his rifle to using a shot gun, which he has frequently to use, however, owing to the danger of using his rifle when there are so many and near neighbors.

Yesterday I induced him to shoot at a target; the result is shown on the opposite page. As will be seen, the second shot hit the nail.

He is quite unassuming and never brags of his feats of skill, and almost everything of this nature relating to him I first learned from others, obtaining a recital of them from him only by dint of questioning. His truthfulness and integrity are beyond question, so that great weight should be given to all he says. $\dagger$

(Signed) E. F. Murray

Santa Barbara Cal[ifornia],

Sept. 11878 .

- Nidever was not 76 until December 20, 1878 .

† Stephen Bowers wrote in the Ventura Observer, December 20, 1892, that "he [Nidever] was much respected in Santa Barbara, where he lived more than fifty years. We never heard his integrity called in question by anyone." 
